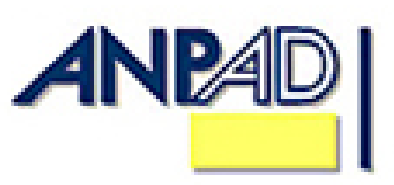

\title{
Identificação ou Resistência? Uma Análise da Constituição Subjetiva do Policial
}

\author{
Identification or Resistance? An Analysis of the Subjective Constitution of Policemen
}

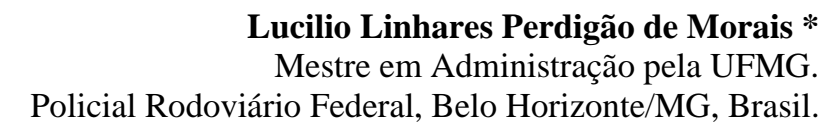

Ana Paula Paes de Paula Pós-Doutora pela FGV/SP. Professora Adjunta da UFMG, Belo Horizonte/MG, Brasil.

\footnotetext{
* Endereço: Lucilio Linhares Perdigão de Morais

Universidade Federal de Minas Gerais, CEPEAD, Av. Antônio Carlos, 6627, Pampulha, 31270-901, Belo Horizonte/MG, Brasil. Email: lucilio.morais@dprf.gov.br
}

Copyright (C 2010 RAC. Todos os direitos, inclusive de tradução, são reservados. É permitido citar parte de artigos sem autorização prévia desde que seja identificada a fonte. 


\title{
RESUMO
}

O presente trabalho objetiva discutir aspectos da construção da subjetividade de policiais. Para tanto investigamse as temáticas da ideologia nas organizações e da formação da identidade profissional. Pretende-se compreender como estes elementos se relacionam na esfera da subjetividade do indivíduo, ocasionando a sua socialização e a consequente adesão ao discurso organizacional. Dessa forma, lançam-se os olhares sobre as questões referentes aos impactos na interioridade do trabalhador das estratégias de controle da subjetividade implícitas na gestão das organizações. Trata-se de uma proposta de pesquisa de natureza qualitativa, na qual, a partir da análise de conteúdo das histórias de vida narradas pelos policiais entrevistados, se procurou compreender a contribuição que os contatos estabelecidos na organização exercem sobre a construção identitária destes. Evidenciam-se algumas das perspectivas que circundam as práticas organizacionais, à procura da conquista do imaginário do trabalhador, bem como as táticas dos trabalhadores à procura da sobrevivência na organização. Em meio a esta relação em busca da dominação, encontra-se a visão de mundo compartilhada pela organização, ora incorporada, ora rejeitada, ora subvertida, em conformidade com a efetiva e particular submersão do indivíduo na organização.

Palavras-chave: ideologia; identidade profissional; subjetividade; policial.

\begin{abstract}
This paper aims to discuss aspects of the construction of policemen's subjectivity. In order to do this we investigated themes such as ideology in organizations and the formation of professional identity. We intend to comprehend how these elements relate to each other in the field of the individual's subjectivity, causing the individual's socialization and his/her consequent adherence to the organizational discourse. In this way we looked into issues related to the impact on the worker's interiority of strategies to control subjectivity, which are implicit in the management of organizations. It is a research proposal of a qualitative nature in which, from the analysis of the content of the life stories narrated by the policemen interviewed, we sought to understand the contribution of the contacts established in the organization to their identitary construction. We highlight some of the perspectives that surround organizational practices, which intend to conquer the worker's imaginary, as well as some tactics used by the workers in order to survive in the organizations. Amid this relation that seeks domination, we find the world view shared by the organization, sometimes incorporated, sometimes rejected, sometimes subverted, in accordance with the effective and particular submersion of the individual within the organization.
\end{abstract}

Key words: ideology; professional identity; subjectivity; policeman. 


\section{INTRODUÇÃO}

As organizações policiais desempenham a relevante missão de garantir a segurança da sociedade e de preservar os demais direitos e garantias fundamentais do cidadão. À polícia incumbe a responsabilidade de manter a ordem pública, garantir a convivência pacífica da população e combater e prevenir os eventos de violência e de criminalidade nas suas mais variadas e complexas causas. Em razão da peculiaridade e da periculosidade dos serviços prestados pelos agentes policiais, essas organizações necessitam de profissionais devidamente habilitados para o correto desempenho das atividades. Torna-se, consequentemente, imprescindível a preparação, além dos procedimentos técnicos que envolvem as atribuições do cargo, para a complexidade de atitudes e habilidades que envolvem o trabalho policial. A entrada do profissional na polícia não se resume ao aprendizado de um conjunto de técnicas. Envolve, principalmente, a construção de novo papel profissional e de nova visão de mundo, que permitirá o desempenho deste papel. Trata-se de verdadeira conversão identitária, que muda a si mesmo a partir da incorporação de novas idéias (Cunha, 2004).

Para a realização desta construção identitária, compartilhando os membros destas organizações dos mesmos sentidos e representando seus papéis de forma integrada, as instituições policiais atuam com foco na subjetividade do indivíduo, objetivando criar a unidade; ou seja, inserir os novos policiais neste sistema social, tornando-os similares aos demais membros desta classe e percebendo-se como diferentes das demais pessoas. Ingressar em uma unidade policial é, portanto, um momento de transição, de impacto, em que a organização passa a ter sentido para o indivíduo, e este passa a compartilhar socialmente as representações que pertinem a esta organização. Trata-se do contato com nova realidade, que tende a produzir efeitos sobre sua interioridade, podendo atuar na forma como enxerga o mundo e as relações que estabelece em sociedade.

A análise da vivência do indivíduo nesta instituição, entendendo como os processos socializadores da organização influenciam a sua subjetividade, é necessária e pode trazer à tona importantes desafios para a compreensão destas organizações. Sob esta perspectiva, o presente trabalho se propõe a compreender em que medida a ideologia vivenciada na organização policial contribui para a formação da identidade profissional do policial. O objetivo é demonstrar que existe na realidade uma relação dialética entre a subjetividade dos policiais e o mundo concreto na formação de sua identidade profissional, pois no mesmo tempo em que há adesão aos pressupostos teóricos da organização, também ocorrem resistências, uma vez que a motivações dos sujeitos são variadas e a pesquisa constatou que muitos deles não estabelecem um vínculo persistente com a organização, de modo que a visão de mundo organizacional pode ser incorporada, rejeitada ou subvertida.

Este artigo está estruturado em quatro partes. A primeira é o referencial teórico, quando se realiza o levantamento bibliográfico das temáticas tratadas, quais sejam: a ideologia nas organizações e a formação da identidade profissional do policial. Posteriormente são apresentados os aspectos metodológicos sobre os quais foi realizada a pesquisa, merecendo destaque o método da história de vida combinado com a análise de conteúdo. A terceira parte consiste na apresentação dos resultados obtidos por mediação da pesquisa, seguida, finalmente, de algumas considerações estabelecidas pelos autores sobre o objeto em análise.

\section{REFERENCIAL TEÓRICO}

\section{A Ideologia nas Organizações}

O termo ideologia é, conforme ensina Eagleton (1997), carregado de variados conceitos no campo das ciências sociais. Seguindo a mesma linha, Löwy (1993) afirma ser difícil encontrar um conceito tão complexo, tão cheio de significados quanto o conceito de ideologia. Na literatura, a ideologia é 
estudada, em regra, em perspectiva macro, sob a ótica dos conflitos de classes, no mundo produzido pelos proprietários e pelo sistema capitalista, no qual a organização aparece exclusivamente como lugar do estabelecimento das relações sociais de produção (Enriquez, 1997). O capital legitima as condições sociais de exploração e dominação dos desfavorecidos. Contudo, cumpre, de antemão, alertar que esta proposta não resume o estudo da ideologia nessa perspectiva. Não obstante se reconheça que a classe dominante do modo de produção capitalista reduz a força de trabalho dos seres humanos à condição de mera mercadoria (Konder, 2002), não é sob essa linha mestra que se procurou desenvolver e analisar o tema.

A ideologia será aqui desenvolvida, prioritariamente, sob uma perspectiva micro, a de visão de mundo, no sentido de se tratar de "um conjunto relativamente bem sistematizado de categorias que fornecem um 'arcabouço' para a crença, a percepção e a conduta de um grupo de indivíduos" (Eagleton, 1997, p. 49). No mesmo sentido, Penafiel and Bellen (2005, p. 28), citando Durkheim, afirmam que a ideologia é "um conjunto de crenças compartilhadas pelo indivíduo na sociedade". A esse conjunto, na medida em que seja coerente, unificado por certa perspectiva social, por uma perspectiva de classe, chama-se de "visão social do mundo" (Löwy, 1993). A ideologia, sob este prisma, mostra como determinado grupo enxerga e interpreta a realidade ao seu redor, uma forma compartilhada de entender e pensar o mundo.

A ideologia exerce uma espécie de padronização dos desejos e comportamentos dos indivíduos que a compartilham (Horochovski \& Taylor, 2001), atuando como ferramenta que interfere diretamente na consciência destes, guiando os seus comportamentos em conformidade com as idéias do grupo. Voltando-se especificamente à preocupação com o termo sob a perspectiva das organizações, percebese que esta visão social de mundo que a ideologia carrega se direciona notadamente para a ação do trabalhador, vislumbrando uma melhoria em sua performance mediante a adesão aos preceitos da organização. É por meio da ideologia que se interioriza e se aceita a regra da organização, possibilitando a conquista do indivíduo e obtendo como resultado final a manutenção da ordem interna e, consequentemente, um ganho de produtividade.

À medida que a organização idealiza as atitudes dos seus empregados, estabelece-se uma espécie de ordem institucional. Cria-se um mito coletivo (Enriquez, 2000), uma ideologia, não permitindo outras visões de mundo. Os valores e as normas são introjetados pelos indivíduos, fazendo-se calar a possibilidade de os sujeitos terem uma vida interior com seu repertório de interrogações e de dúvidas. O indivíduo, com todas as suas particularidades, é superado em nome de um conjunto homogêneo que, acredita-se, pode oferecer melhor desempenho à organização. O discurso ideológico da organização produz crenças e vende ilusões ao trabalhador (Freitas, 2000). Acima dos questionamentos e das peculiaridades de cada trabalhador, são colocados os ditames organizacionais, que, incorporados pelo indivíduo, se tornam divinos, inquestionáveis, uma espécie de viseira, só permitindo um caminho para a visão.

Alimentado do discurso ideológico, o indivíduo, aqui trabalhador, é impulsionado a enxergar a realidade em conformidade com o conjunto de respostas que lhe foram oferecidos pela organização. Eliminam-se as reações em sentido contrário. O grupo é coeso e ciente das necessidades de executar as tarefas conforme prevêem os regulamentos da organização. Os regulamentos e demais padrões de conduta são cumpridos não somente porque são ordens superiores, mas, em especial, porque são inquestionáveis, pois já pertencem à interioridade do trabalhador. Enriquez (2000) chama essa persuasão de doença da idealização, uma vez que a organização busca não somente a idealização dos valores da empresa pelo indivíduo, mas sim “o seu amor e a sua devoção incondicionais” (p. 15). Nessa lógica, produzir mais e oferecer melhores resultados para a organização não tem somente o caráter efetivamente econômico e lucrativo de toda e qualquer atividade empresarial, mas também significa agir em conformidade com os seus próprios valores, visto que os valores organizacionais impregnaram o indivíduo. Mantém-se, assim, o estado imutável das coisas, a força da inércia (Enriquez, 2000), evitando-se qualquer tipo de transformação social. A organização revela-se como um espaço social de comportamento controlado. 
Para Ramos (1989) essa racionalidade da organização vai além da simples manutenção do estado das coisas. Sua denúncia é de que esta suposta razão é, na verdade, um instrumento disfarçado de repressão social, com o gravame de que invade a própria subjetividade do indivíduo. O discurso organizacional, muito além da manutenção da coesão interna, forma indivíduos silentes, irrestritamente adeptos da empresa. Como resultado, cala-se a possibilidade de questionamentos e divergências. O trabalhador está adequado ao que preconiza a organização. É certo que não questiona os valores emanados da empresa, pois se preocupa com a preservação da organização, à qual está atrelado o seu próprio sucesso e a quem nutre um sentimento de profunda devoção (Berger \& Luckman, 1985).

Nesse sentido, a sanidade do indivíduo está diretamente relacionada com a sua adesão ao discurso ideológico da organização. Ou seja, normal é o sujeito que abre mão de sua autonomia individual, ajustando-se ao contexto da organização. A socialização do sujeito neste espaço corresponderá, por conseguinte, à sua alienação, reduzindo o indivíduo e adequando-o à organização. Esquece-se até mesmo de que a abertura de espaços para a transformação social pode também ser produtiva para a instituição. Depreende-se, portanto, que as relações estabelecidas dentro da organização não são limitadas à produção. O espaço organizacional é, também, um local de construção social do indivíduo. O discurso ideológico da organização que o indivíduo carrega consigo vai implicar consequências não somente nas relações que serão estabelecidas neste grupo, mas também em sua forma de enxergar a realidade e a sociedade.

\section{A Formação da Identidade Profissional do Policial}

O policial faz aquilo que Hughes (1962), Conforme cita Carmo, Oliveira e Arruda (2006), chama de dirty work, ou seja, tarefa socialmente degradante. As polícias e seus policiais lidam com a escória do sistema social (Cruz, 2005), aqueles que os normais (Goffman, 1975) esperam que sejam mantidos fora de seu contato pelo Estado. Tais tarefas, embora degradantes para a sociedade, são imprescindíveis para que os demais membros desta possam conviver de forma civilizada. Considerando as atribuições profissionais dos policiais, espera-se que o indivíduo que lida com essas funções se trate de um verdadeiro super-homem (Soares \& Musumeci, 2005), um guerreiro bravo, com força física e aptidão para o risco, uma vez que está incumbido da árdua missão de coibir a prática de crimes, retirando os criminosos da sociedade.

O serviço policial, dado o âmbito e a particularidade de sua atuação, bem como o fato de ser imprescindível, carece de determinadas representações (Goffman, 1985) para o desempenho do seu papel. Trata-se do desenvolvimento de uma identidade coletiva, uma integração que orienta o relacionamento interpessoal. A organização promove a imersão do indivíduo em nova realidade. Estabelece-se uma relação de dominação, que serve de instrumento para consolidar o conjunto de valores que dão sustentação à instituição (Listgarten, 2002). No papel de policial, o indivíduo tem o dever de incorporar um vasto repertório de dramatização (Goffman, 1985), pertencente ao status social de sua função.

Como a identidade profissional faz parte de um construto que considera a introjeção de novo universo simbólico, para tornar-se policial é necessário, em algum momento, romper com o universo primariamente construído (Berger \& Luckman, 1985), com descontrução e reconstrução da subjetividade (Silva, 2006), para que sejam incorporados os papéis que possibilitem a representação social: determina o comportamento social da pessoa e controla as suas atitudes. Nesse processo, chama a atenção nas unidades policiais a doutrinação do indivíduo, (Martins \& Bulgacov, 2006), transmitindo a ideologia que se aplica naquele contexto, padronizando suas ações em conformidade com os ditames organizacionais (Silva, 2006). Busca-se mobilizar e ajustar vários mecanismos do ser humano, desde a ação motora até as operações mentais, alterando o comportamento deste, no sentido de garantir maior rendimento e performance para a organização (Roux, 1983).

Os policiais, desde seu primeiro contato com a instituição, são submetidos à incorporação do perfil necessário para o desempenho das atividades inerentes à profissão (Cunha, 2004). Muito mais que a 
aprendizagem de determinadas competências indispensáveis para o exercício da profissão, é necessária uma (re)construção do self (Silva, 2006), bem assim a conversão identitária, transformando a si mesmo e incorporando novo conjunto de idéias, concepções e valores a respeito do novo papel que deverá desempenhar profissionalmente.

As organizações policiais podem ser vistas, portanto, como estufa de mudar pessoas, em que cada um é um experimento natural sobre o eu ideal que se pretende atingir, relembrando algumas práticas das instituições totais (Goffman, 1974), aqui definidas como os locais nos quais residência e trabalho se confundem, havendo um elevado número de indivíduos que, na mesma situação, levam uma vida fechada e formalmente administrada por considerável período de tempo. Instituições com estes tipos de práticas apresentam fortes tendências ao fechamento, isto é, isolamento dos participantes em relação ao restante do mundo.

Em seguida ao processo de mortificação do eu (Goffman, 1985) e à consequente degradação do ser humano, a Instituição passa ao processo de construção do novo eu. Assim, inicia-se o adestramento do indivíduo para a incorporação do perfil demandado. Esse adestramento (Roux, 1983), manifestado por meio do controle do comportamento e das atitudes do indivíduo, uniformiza as diferenças, submetendo a particularidade de cada pessoa a formas de controle e a padrões de conduta que idealizam a obediência irrestrita aos códigos da organização policial.

Um dos principais objetivos que se apresenta neste intenso processo de socialização a que estão submetidos os policiais é a construção de barreiras simbólicas com o mundo externo. A formação da identidade profissional do policial pode ser vista, portanto, como ritual de passagem a fim de desenvolver nos policiais o espírito de corpo (Soares \& Musumeci, 2005), tornando-se iguais entre si e diferentes dos demais, incorporando devidamente o papel a ser representado em sociedade. Valorizase a "solidariedade para dentro e o distanciamento para fora" (Goffman, 1985, p. 174) como meio de garantir a existência tanto da corporação como de seus membros.

Percebem-se, assim, aspectos importantes da formação policial como verdadeira fabricação do formato de atuação profissional (Cunha, 2004). A partir dos mais variados rituais de exposição do indivíduo, demonstra-se o que se espera de um policial daquela organização, assim como o conjunto de atitudes que não o exporá de forma negativa perante sua equipe de representação, a polícia. Consegue-se, ainda, colocar o indivíduo, policial, em posição de distanciamento em relação aos demais membros da sociedade, preservando, supostamente, a organização, seus integrantes e os seus valores.

O indivíduo é incluído no grupo social ao qual pertence (Goffman, 1985), assumindo para si as interpretações e conclusões sobre o papel que tem a desempenhar em sociedade. O soldado torna-se algo que se fabrica que, dada uma figura ideal, torna-se uma máquina. Para tanto, a Instituição corrige as posturas indesejadas e se apropria do indivíduo - "foi 'expulso o camponês' e lhe foi dada a 'fisionomia de soldado" (Foucault, 1977, p. 115). A conduta do trabalhador está pronta e em conformidade com as normas descritas pela polícia.

Nessas organizações, os treinamentos não apenas qualificam a força de trabalho, mas também submetem os trabalhadores à ideologia dominante (Faria, 1987), assegurando a dominação do indivíduo e fazendo com que este desempenhe o papel que representa a sua classe conforme lhe foi devidamente determinado, não restando espaço para conflitos ou quaisquer questionamentos, ainda que em prejuízo de possíveis avanços. As organizações são espaços de comportamento controlado e, como todo o controle social, passa necessariamente pelo controle da identidade do indivíduo (Freitas, 2000). Para exercer este controle, é necessária a uniformização, reduzindo a complexidade humana, de forma a automatizar o comportamento do indivíduo. O policial é tratado como mais um recurso, dentre tantos outros, do sistema responsável pela garantia da segurança pública da sociedade. Mediante o treinamento e a convivência coletiva, as organizações disseminam os seus valores (Faria, 1987), tornando a formação profissional um momento de achatamento da individualidade (Roux, 1983), no qual, pela desqualificação da singularidade do indivíduo, se alcança um todo uniforme, capaz de atender aos padrões performáticos e de comportamento estabelecidos pela organização. 


\section{ASPECTOS METODOLÓGICOS}

Considerando os objetivos propostos para este trabalho, bem como a pergunta que norteia todo o processo de pesquisa, coleta e análise dos dados, optou-se pelo estudo de natureza qualitativa. Segundo Vergara (2005), os procedimentos qualitativos focalizam as peculiaridades e as relações entre os elementos. Enfatizam o que é significativo e relevante, embora possa não ser necessariamente frequente no texto. A pesquisa qualitativa pode oferecer, assim, maior possibilidade de respostas às inquietações ligadas às dinâmicas identitárias, extrapolando as categorias analíticas e explicativas das pesquisas de natureza quantitativa, já que a temática tratada neste trabalho, dada a sua subjetividade, necessita de percursos metodológicos que possibilitem a captação das singularidades da vivência de cada indivíduo.

Como unidade de análise, escolheram-se a identidade profissional e a ideologia nas organizações. Tal temática foi tratada a partir da procura pela compreensão sobre como a exposição do indivíduo ao discurso ideológico - visão de mundo - da organização em estudo contribui para a sua socialização neste grupo, formando sua identidade profissional. A partir deste caminho, procurou-se responder ao problema objeto desta pesquisa já anteriormente apresentado, qual seja: Em que medida a ideologia vivenciada na organização policial contribui para a formação da identidade profissional do policial?

Como unidade de observação foi escolhida uma organização policial do Estado de Minas Gerais, a $4^{\mathrm{a}}$ Superintendência Regional de Polícia Rodoviária Federal/ MG - 4 SRPRF/MG.

A Polícia Rodoviária Federal encontra-se presente em todo o território nacional, com 21 (vinte e uma) Superintendências Regionais de Polícia Rodoviária Federal e 5 (cinco) Distritos Regionais de Polícia Rodoviária Federal. As Superintendências se desconcentram nos Estados por meio de unidades administrativas, denominadas delegacias, que, por sua vez, se desconcentram por meio de postos de fiscalização. O efetivo aproximado é de 10 (dez) mil policiais, sendo responsável pelo patrulhamento ostensivo de toda a malha rodoviária federal, algo em torno de 55 mil quilômetros de rodovias e estradas.

Embora seja uma instituição de âmbito nacional, a escolha pela delimitação em Minas Gerais se deu, basicamente, pela conveniência da pesquisa, haja vista que se tratou de órgão que facilita o contato com os entrevistados, dadas as limitações temporais e financeiras do presente trabalho, bem como a receptividade apresentada por seu dirigente máximo, dando ampla abertura para a realização das entrevistas. Some-se a isso o fato de tratar-se do Estado com a maior malha viária federal do país, sendo a $4^{\text {a }}$ SRPRF/MG, consequentemente, a maior Superintendência, contando com 18 delegacias e cerca de 44 postos. O efetivo é de pouco mais de 900 policiais, ou seja, cerca de $9 \%$ (nove por cento) do número total de policiais do órgão.

Os sujeitos da pesquisa foram selecionados pelos critérios da acessibilidade e da tipicidade (Vergara, 2006). Por acessibilidade entende-se, aqui, a facilidade de acesso, enquanto por tipicidade foram selecionados elementos que o pesquisador considerou representativos deste grupo, garantindo a diversidade entre os entrevistados. Seguindo esses pressupostos, foi possível ouvir homens, mulheres, policiais de diferentes idades e lotados em locais diversos e em diversas situações. Tal diversidade possibilitou compreender nuanças específicas da formação destes indivíduos, assim como visualizar o que há de comum em suas experiências profissionais.

Não foi previamente definido o número de entrevistas a serem realizadas, pois foi durante o trabalho de produção dessas entrevistas que o número de entrevistados necessários começou a se descortinar com maior clareza, uma vez que, conhecendo e produzindo as fontes de sua investigação, o pesquisador adquiriu condições para avaliar o grau de adequação do material já obtido aos objetivos do estudo. À medida que os dados começaram a se repetir nas entrevistas, chegou-se ao ponto de saturação (Alberti, 2004,). Neste momento, as entrevistas foram encerradas. Nessa linha, foram ouvidos 10 (dez) policiais. 
Os entrevistados foram selecionados por meio da estratégia da bola de neve (Camargo, 1984; Marre, 1991). Ou seja, a partir da verbalização das primeiras pessoas entrevistadas foi possível estabelecer as articulações a serem investigadas e as pessoas a serem entrevistadas, garantindo a diversidade qualitativa (Alberti, 2004) do método na reconstrução do objeto de estudo.

Objetivando preservar a identidade dos entrevistados, não será apresentada no trabalho uma descrição pormenorizada das particularidades que permeiam cada história de vida. Contudo, para que o leitor não perca a oportunidade de enriquecer as suas conclusões sobre a pesquisa, algumas linhas gerais dos sujeitos selecionados para a pesquisa necessitam ser consideradas. Quanto ao gênero, foram ouvidos oito homens e duas mulheres. As faixas etárias são diversificadas, com quatro sujeitos com idade entre vinte e quatro e vinte e seis anos e cinco com idade entre trinta e quatro e trinta e nove anos. Um entrevistado não quis revelar a idade.

O método adotado para a coleta de dados foi o da história oral, com foco na história de vida, vislumbrando a compreensão dos processos ideológicos que compõem o processo socializador de formação da identidade profissional do indivíduo policial nesta organização como um todo, desde sua vida anterior à entrada na instituição até a sua situação atual.

A partir da história oral, metodologia voltada à pesquisa de temas contemporâneos, tanto nos estudos organizacionais como em outros campos das ciências sociais, objetivou-se a "recuperação do vivido, conforme concebido por quem viveu” (Alberti, 1989, p. 5), recorrendo à memória do entrevistado como fonte principal para a construção do conhecimento (Neves, 2001). Nesse procedimento metodológico, a instância da memória norteia as reflexões, acarretando desdobramentos importantes para a realização da pesquisa. O grande fascínio da história oral está em permitir ao pesquisador a possibilidade de vivenciar as experiências do outro, compreendendo as expressões de sua vivência (Alberti, 2004).

Considerando o "âmbito subjetivo da experiência humana" (Ferreira \& Amado, 2002, p. 129) como parte central, a história oral favorece o estudo das representações estabelecidas pelos indivíduos no contexto social, evidenciando, dessa forma, o alcance daquilo que possa estar implícito nos fatos narrados, produzindo muito mais que simples relatos ordenados da vida e da experiência dos outros. A interação do pesquisador com o pesquisado confere à história oral a característica de, ao mesmo tempo, reconstruir fatos históricos e entender determinadas representações.

Com os relatos orais estabelecidos pela memória da história de vida do indivíduo, a análise pode ser enriquecida e ser mais abrangente, considerando como em diversos indivíduos, de origens e formações diferentes, determinada passagem influenciou suas percepções no futuro. A partir dessa variedade de sensações e interpretações, as conclusões ficam fortalecidas e assumem relevância. A abordagem da história de vida representa um caminho propício para chegar mais perto da história vivida pelo sujeito. A idéia central, ao pesquisar a história de vida, é a de não construir uma única história, mas perceber as várias histórias construídas.

Como ferramenta para a coleta dos dados, realizou-se entrevista não estruturada. Para tanto, foi utilizado um breve roteiro, com temas centrais a serem tratados, nada rígido, privilegiando a construção de um mapa, e não uma camisa de força (Neves, 2001), permitindo a condução dos trabalhos de forma bastante flexível, valorizando a riqueza da interação do entrevistado com o entrevistador. As entrevistas realizadas foram gravadas, após a devida autorização dos entrevistados, e transcritas para que então fossem realizadas as análises.

Na análise dos dados obtidos, o tratamento foi realizado com base na análise de conteúdo (Bardin, 2005), com o propósito de efetuar um estudo minucioso do conteúdo que compõe tanto as transcrições das entrevistas quanto os documentos levantados, captando as idéias essenciais que integram estas fontes (Laville \& Dionne, 1999). A análise de conteúdo aplica-se ao estudo de textos e documentos (Vergara, 2005).

Favorece, portanto, a compreensão dos significados dos símbolos e linguagens utilizadas, a fim de descrever os fenômenos estudados, a identidade profissional, a ideologia e a socialização do indivíduo 
nas organizações, uma vez que a finalidade da análise de conteúdo é aumentar a qualidade inferencial dos resultados, estabelecendo sua devida relação com o contexto (Vergara, 2005).

Para a realização da análise de conteúdo, empregou-se a técnica da grade aberta de análise, apoiada na análise das respostas às questões abertas (Bardin, 2005). Nesta técnica, as categorias de análise foram identificadas pelo pesquisador durante a pesquisa. Dessa forma, puderam ser rearranjadas durante o andamento da pesquisa, estabelecendo-se, após o rearranjo destas, as categorias finais de análise, em conformidade com a análise destas respostas, que exploraram a identidade profissional e o discurso ideológico da Instituição e a socialização do indivíduo na organização. Nessa linha, o trabalho de análise foi estruturado considerando três momentos principais: a vida do indivíduo anteriormente ao seu ingresso na Instituição; a vivência social na Instituição; e o seu futuro. Para cada um desses momentos, procurou-se agrupar as significações atribuídas em categorias, possibilitando melhor compreensão do todo, bem como das peculiaridades do ingresso na polícia para cada indivíduo.

\section{A CONSTITUIÇÃo SUBJETIVA DO POLICIAL: IDENTIFICAÇÃo OU RESISTÊNCIA?}

\section{O Ingresso na Organização}

No que se refere às origens destes entrevistados, não há, num primeiro momento, como se falar no estabelecimento de categorias que possam ter implicado a escolha por esta profissão e, consequentemente, por trabalhar especificamente nesta organização. É latente a diversidade de histórias de vida, cada uma com as suas particularidades e complexidades.

Os policiais ouvidos possuem escolaridade desde o nível médio até o terceiro grau com pósgraduação. Em que pese a habilitação exigida para o preenchimento do cargo no concurso público ser somente o nível médio, ingressaram neste órgão jornalistas, economistas, engenheiros, médicos e veterinários, dentre outras profissões. As experiências profissionais também são variadas, sendo a PRF para alguns o primeiro emprego e para outros mais uma experiência em órgão público. Há, ainda, aqueles que vivenciam neste cargo o rompimento com as atividades que vinham desempenhando e para as quais se habilitaram: o engenheiro que deixa de gerenciar uma obra, o médico veterinário que deixa de clinicar e o jornalista que abandona os órgãos de imprensa. Todos estes caminham num só sentido, a atividade policial, atuando na segurança pública nas rodovias federais.

Percebe-se, contudo, que, apesar das múltiplas origens e da manifesta impossibilidade de agregar estes indivíduos em categorias que favoreçam a análise, há um ponto em comum, o qual surge justamente ao tratar da escolha por esta profissão - ser policial - e, especificamente, por trabalhar nesta organização policial, a Polícia Rodoviária Federal.

Implícita ou explicitamente, as falas convergem para a busca pela aprovação em concurso público, garantindo estabilidade e remuneração satisfatória, desvinculando-se das regras da iniciativa privada. Esta opção é presente, de forma unânime, na fala dos entrevistados.

"Por que eu escolhi ser policial? Nunca passou pela minha cabeça que eu queria ser policial um dia. Eu nunca tinha planejado isso. [...]. Foi a estabilidade e o salário, que é bom!” (Entrevistado 3)

“O concurso público foi uma oportunidade de estabilidade, de salário, condição financeira.” (Entrevistado 2)

"Mas por que a Polícia, quero dizer, por que a polícia, por que se tornar policial? Eu, desde a minha infância, não me imaginava como policial, não me imaginava assim. Eu tinha medo de polícia, quando era pequeno. Tinha medo de polícia. E depois que fui amadurecendo, meus olhos nunca brilharam, quando eu pensava [...] Eu nunca cogitei a possibilidade de me tornar policial. Nunca cogitei, talvez por falta de conhecimento, porque a imagem que eu acho que todo o mundo tem, [...]. E eu, obviamente, fui para o lado do concurso público; mas, à primeira vista, obviamente, por causa do dinheiro”. (Entrevistado 1) 
"Bom, como eu falei, eu entrei na Polícia Rodoviária Federal por ser um concurso, o concurso mais comentado da época. É uma carreira que dá certo status, certa projeção antes de entrar! Dá certo status, certa projeção e dá certa estabilidade financeira, além de outras coisas que a carreira provê”. (Entrevistado 7)

Buscando extrapolar um pouco o que está evidente nestas falas, a escolha pelo cargo público e, como consequência, a procura de uma relação de trabalho baseada na estabilidade, com remuneração fixa e compatível com as atribuições do cargo desempenhado, é necessário destacar algumas questões que estas afirmativas despertam.

Primeiramente, é interessante notar que a escolha pela carreira policial na organização analisada não apresenta, explicita ou implicitamente, um liame subjetivo do indivíduo com a PRF. Muito pelo contrário, as narrativas são centradas no fato de esta profissão não ter sequer sido cogitada ao longo de sua construção como sujeito, chegando alguns entrevistados até a expressar uma prévia repulsa quanto à atividade policial e às representações inerentes a esta profissão (Goffman, 1985).

“[...] inicialmente, polícia para mim foi meio repulsivo. Polícia, nossa, de jeito nenhum! Mas depois que eu comecei a amadurecer a ideia, aí eu comecei a ver o lado bom de ser polícia e comecei a gostar da idéia”. (Entrevistado 10)

Um ponto que merece atenção na escolha destes entrevistados refere-se à remuneração. Sendo, conforme dados do Ministério do Planejamento, Orçamento e Gestão, a carreira de nível médio de maiores vencimentos no âmbito do Poder Executivo Federal, alcançando colocação privilegiada, até se comparada às carreiras de nível superior, este cargo torna-se bastante atraente aos concurseiros.

Nesse sentido, a escolha pela carreira policial passa longe da procura pelo desempenho dos atributos pertinentes à função e a suas especificidades, os quais parecem não ser considerados durante o processo de preparação para o referido concurso. A combinação de remuneração e estabilidade no emprego justifica o rompimento do indivíduo com todo o seu projeto de vida, com toda a sua construção profissional e seus consequentes vínculos, ocasionando o seu interesse pelo ingresso na Polícia Rodoviária Federal ou em qualquer outro órgão público que lhe oferecesse as condições que a iniciativa privada não lhe oferece.

No término desta seção, fica latente o aparecimento de uma categoria mediante a qual se pode compreender, na multiplicidade de origens destes indivíduos, a convergência para esta nova ocupação, implicando a entrada na organização em estudo. Esta categoria é aqui denominada de concurseiro, termo utilizado para definir os indivíduos que procuram um vínculo de trabalho com as especificidades oferecidas pelo serviço público. A escolha pela profissão e pela organização é, em regra, independente das características do trabalho a ser executado, mas associadas ao tipo de relação com o empregador, em especial no tocante à remuneração, com plano de cargos e salários previamente definido e desvinculado da produtividade. Destaca-se, também, a estabilidade no emprego, cuja demissão somente pode acontecer em hipóteses previstas em lei, notadamente voltadas para casos de prática de ilícitos pelos agentes públicos, desvinculando-se da incessante busca pelo aumento da produtividade do trabalhador.

\section{A Vivência Social na Instituição}

Levantados alguns aspectos referentes à escolha pela profissão, é chegado o momento de entrar no emaranhado (Cunha, 2004) da socialização do indivíduo que ingressa na Polícia Rodoviária Federal, buscando descrever e interpretar as táticas adotadas pela organização para a dominação de sua subjetividade (Paes de Paula \& Wood, 2002). A relação imaginária (Faria, 2005) criada permite a incorporação das crenças e dos valores, bem como do modo de ser e de agir deste grupo, favorecendo a coesão interna entre os trabalhadores, policiais e, consequentemente, a manutenção da ordem institucional (Enriquez, 2000).

Sob a perspectiva de melhor compreender as questões atinentes à subjetividade nesta organização (Lapierre, 1994), a pesquisa voltou-se para a procura pelos laços afetivos, imaginários e psicológicos, 
estabelecidos pelo indivíduo (Freitas, 2000) em seu convívio organizacional, servindo de fonte para a sua própria construção. Nesta linha, a inserção no espaço organizacional é um momento de embate entre os valores organizacionais e os valores individuais, sendo que o sujeito, em sua interioridade, e com toda a sua complexidade (Machado \& Crubellate, 2006), age e reage conforme a sua percepção, a forma como interage e se posiciona diante dessas normas.

O processo de representação do papel (Goffman, 1985) de policial é um momento de transformações, a partir do qual as relações sociais estabelecidas na organização são internalizadas, transcendendo (Vigotski, 2003) para o individual. Essas vivências transitam da exterioridade para a interioridade, passando a pertencer à subjetividade do indivíduo, para atuar $\mathrm{Na}$ sua forma de enxergar o mundo.

Nessa linha, a percepção do indivíduo sobre o desempenho dessa função passa, necessariamente, pela comparação entre como era percebido o trabalho policial anteriormente ao ingresso na polícia e como é agora, procurando revelar como este processo socializador atua sobre sua subjetividade.

Perguntados sobre possíveis mudanças na percepção do trabalho policial após o ingresso na PRF, os policiais passaram a relatar os laços estabelecidos com a organização e com a profissão que desempenham/representam os vínculos afetivos, o compromisso com o trabalho e a expectativa de um melhor reconhecimento da profissão e de suas demandas, em especial no tocante às questões estruturais do órgão.

"Depois que eu entrei, que eu conheci melhor, comecei a ver que há vários ângulos. Tem o fator de criminalidade, que eu achava antes que a PRF não tinha contato. A questão dos acidentes também, que eu não tinha essa noção de que é a gente primeira pessoa a chegar no acidente, a dar aquele apoio.” (Entrevistado 10)

"Então, minha visão mudou muito. Antigamente, se pensava que não fazia nada. Depois que eu vi, eu vi que se faz muito, faz muito mesmo.” (Entrevistado 7)

Considerando que a escolha pela profissão não foi motivada inicialmente pela vocação profissional, mas sim pelas questões anteriormente elencadas na procura pelo emprego público, as afirmativas reforçam o pouco conhecimento prévio do trabalho do policial rodoviário federal. Retratase, além do incômodo quanto às questões estruturais que circundam o funcionamento de qualquer órgão público, a surpresa diante do conjunto de atribuições que exerce um PRF, bem como um prévio medo, ou ansiedade, em relação ao perigo que se enfrenta nesta atividade.

Ressaltam-se, ainda, a admiração e o reconhecimento pela relevância desta organização, sua importância para a sociedade, até mesmo se comparada às demais instituições de segurança pública no País. Estas falas indicam que o indivíduo está entrando em contato com o discurso ideológico da organização, interagindo, ainda que de forma limitada, com as representações inerentes ao cargo. O medo e a consideração de um trabalho não tão relevante são substituídos pela incorporação do espírito de braveza, assumindo sua condição de super-homem (Soares \& Musumeci, 2005), alguém diferenciado dos demais, apto a assumir o risco que faz parte do seu cotidiano, enchendo de nobreza a sua missão.

Vislumbrando complementar a análise da inserção destes indivíduos na organização em estudo, os entrevistados foram perguntados se consideram o trabalho policial diferente dos demais. Surge aí o reconhecimento da peculiaridade do serviço que desempenham, traduzido na responsabilidade pela manutenção da paz social, evitando os eventos de criminalidade e mantendo afastados da sociedade os criminosos, enfim, o serviço sujo (Hughes, 1962), do qual os normais (Goffman, 1974) esperam ser mantidos a distância. A polícia - e, por conseguinte, os policiais - exerce a função de "pára-choque" (Entrevistado 1) social, lidando com aqueles que estão à margem da sociedade.

“[...] é o pára-choque social que [...] e a gente está vestindo um uniforme. A gente está num emprego onde a gente tem a obrigação de enfrentar o crime, e a gente não é simplesmente um espectador, a gente não pode ficar alheio. Então, por esse motivo, eu acredito, sim, que seja uma profissão diferente, mas também com 
algumas, pelo fato de ser uma profissão em que se lida com criminoso, quero dizer, mais com a margem da sociedade”. (Entrevistado 1)

"Mudou, mudou. Hoje, tenho plena consciência de que o trabalho policial envolve muito mais risco do que você percebe em geral. O risco pessoal, para o policial, ele é muito alto em qualquer coisa que ele vai realizar. Dobrar a esquina com uma viatura já é um risco, porque a gente não sabe o que vem depois de cada esquina”. (Entrevistado 2)

A periculosidade do trabalho, o risco e as questões atinentes à segurança são temáticas que trazem à tona a forma como este indivíduo enxerga a necessidade, entrando na polícia, de promover uma mudança de comportamento. O descortinamento deste mundo desconhecido implica o reconhecimento de uma profissão diferenciada, que carece de representações específicas para o seu desempenho, cujos fatos vivenciados extrapolam as relações de trabalho. "Uma profissão que precisa de coragem" (Entrevistado 3).

Como resultado das peculiaridades da inserção do indivíduo na organização estudada, depreende-se que o ingresso na polícia muda a vida do indivíduo.

"Quando eu entrei na polícia e até um ano e meio depois de estar na polícia, eu acho que, tipo assim, eu selecionei mais minhas amizades, eu comecei a ter outra visão das pessoas que estavam no meu meio, comecei a observar mais o meio em que eu vivia e, às vezes, eu fiquei até mais fechado no início. Fiquei até mais fechado. Mas, depois e tal, eu acho que esse processo me endureceu, mas não tenho esse negócio, não”. (Entrevistado 7)

"Pensando em três anos atrás, quatro anos atrás, mudou, sim. Mudou por o policial, às vezes, ter que ter uma atitude mais firme. Isso mudou um pouco, porque eu deixei de ser um pouco passivo em algumas situações. A hora que você tem que agir, quando você tem que falar, ao invés de só ouvir aquilo. Agora, eu já tenho uma reação de, pelo menos, opinar, pelo menos, dá uma opinião naquilo que eu acho. Eu acho que isso foi uma das coisas que mudou. E a rotina também. A rotina diária. Ser policial muda”. (Entrevistado 3)

"Eu acho que eu mudei, sim. Eu acho que eu amadureci, porque agora eu tenho uma imagem por trás do [...], que é a imagem de uma instituição pública que é a instituição policial, que tem uma disciplina por trás, que tem um senso de organização, um senso de prudência, de responsabilidade que toda instituição policial tem que refletir, que o público espera. E eu acredito que eu tenha captado esse espírito de ser um cara mais responsável, mais maduro. E acredito que sim, que eu tenha evoluído nesse aspecto, que a polícia tenha mudado minha vida nesse sentido”. (Entrevistado 1)

"Mudou. Conheci muito o lado negro da vida da sociedade, da criminalidade. A gente tem que prestar atenção nas coisas e saber como é a realidade ali. Então, você fica a par de muitos fatores aí. E, por isso, eu comecei a ficar mais alerta às situações, um pouco mais estressado também, vigilante, preocupado. Então, gerou um estresse geral. Agora, já estou mais adaptado”. (Entrevistado 9)

"O fato de você passar a ser policial, você tem toda uma visão diferente da sociedade, uma maneira mais atenta de agir, mais crítica de analisar notícias voltadas à violência, à criminalidade, que é a situação que a gente vive hoje, a parte do serviço público que dá uma estabilidade. Tudo isso mudou drasticamente a minha vida”. (Entrevistado 8)

Afora as questões relacionadas à estabilidade financeira, obtida a partir da aprovação no concurso público, alcançando melhor remuneração e relação de trabalho que lhe permite ganhar mais e, consequentemente, gastar mais (Entrevistado 5), o contato com o lado negro da vida da sociedade (Entrevistado 9) atua sobre a subjetividade do indivíduo, influenciando sua postura na decisão sobre as pessoas que serão de seu convívio. Enfim, verifica-se a necessidade de adaptação a essa nova realidade que a organização lhe propiciou, a necessidade de, efetivamente, agir como policial, representando o papel que lhe foi dado (Goffman, 1985) de forma a honrar o nome da Instituição policial cuja imagem carrega por trás (Entrevistado 1). 


\section{Perspectivas para o Futuro}

Encerrando a interação com os entrevistados, foi aberta a oportunidade para que falassem sobre as suas perspectivas para o futuro. A pergunta não foi direcionada, mesmo quando requerido um limite pelo entrevistado, pessoal ou profissional, em determinada esfera da vida destas pessoas. Entretanto a necessidade de falar voltou-se totalmente para os aspectos relativos às perspectivas profissionais.

Ao procurar compreender as falas sobre o futuro - em especial, o profissional - destas pessoas, foi necessário resgatar a própria razão de escolha pela Polícia Rodoviária Federal a da procura pelo emprego no setor público. Estes indivíduos, na medida em que ingressaram nesta organização notadamente em decorrência da procura pela relação de trabalho oferecida, e não por uma prévia identificação com a profissão ou com o órgão, almejam o crescimento profissional visando não a progressão e evolução na carreira que integram, mas sim à melhoria da relação de trabalho na qual já se encontram. Nesse sentido, a perspectiva para o futuro é o crescimento por meio da aprovação em outro concurso público que ofereça, em especial, uma melhor remuneração.

“O meu futuro, o que eu enxergo para mim, é um futuro sem a Polícia Rodoviária Federal. Mas não por mágoa, não por nada, nenhum sentimento negativo com relação à polícia. Aprendi a gostar muito do serviço, mas eu acredito que eu (Entrevistado 1) tenho condições de buscar uma coisa mais além para minha vida e, obviamente, que a polícia vai, se ela se tornar parte do meu passado, vai se tornar uma parte alegre para mim. [...]. Obviamente, eu sempre busco um incremento do lado financeiro.” (Entrevistado 1)

"Então, eu vou me formar e fazer, talvez, outros concursos públicos e correr atrás de outras coisas para mim”. (Entrevistado 2)

Sair da polícia é, por conseguinte, uma consequência natural para estas pessoas. Não obstante o carinho, os laços afetivos estabelecidos com esta organização, os policiais querem mais. Ser aprovado em outro concurso público, obtendo uma melhor remuneração, é algo que se espera como resultado do crescimento profissional destes indivíduos. A polícia fica na memória, uma passagem sem mágoas e de afeto, uma parte alegre que fica para trás nesta ascensão dentro do serviço público.

Ou seja, o indivíduo, como concurseiro que é, está pronto para as oportunidades de uma melhor colocação no serviço público. Apesar de ter passado por essa experiência de forte carga subjetiva com a organização, torcendo por uma melhor valorização e consequente reconhecimento do órgão, trabalhar na Polícia Rodoviária Federal não se coloca necessariamente em seu futuro. A prioridade continua sendo a realização profissional a partir dos benefícios conquistados, e não necessariamente pelo trabalho a ser desempenhado. O indivíduo, ainda que imerso na organização, preserva as suas expectativas pessoais, a sua realização, ainda que não consonante com a do órgão.

Mesmo quando o interesse profissional passa pela permanência na polícia, as falas não se situam em galgar o crescimento dentro do órgão ou em oferecer uma contribuição de alguma forma substancial para a Polícia Rodoviária Federal, mas sim o fato de trabalhar num lugar que se ajusta às pretensões do indivíduo.

Merece, ainda, destaque que estas pessoas, embora se desviem da organização, ao traçar seus próprios planos, retornam impreterivelmente ao capital, visto que o aspecto financeiro é parte integrante e definidora da sua suposta independência quanto aos valores organizacionais. De certa forma, desvincula-se com facilidade da organização; mas, em outro sentido, aproxima-se da lógica que mantém o funcionamento deste sistema, a lógica do capital, da qual o indivíduo não deixa de se prender. Muda somente a forma de realização, a estratégia para se chegar a um mesmo caminho.

Nessa linha, evidencia-se a ideologia na perspectiva tratada no referencial teórico como macro, abandonada num primeiro momento. Ou seja, não obstante o termo tenha sido tratado neste trabalho numa perspectiva aqui denominada como micro, designando as crenças e os valores compartilhados pelos membros da organização, remonta-se ao seu caráter macro, sendo o dinheiro um elemento essencial no funcionamento do mundo capitalista em que vivemos (Konder, 2002), atuando decisivamente nas escolhas pessoais. 


\section{CONSIDERAÇÕES FINAIS}

À luz da teoria pesquisada, foi possível vislumbrar, com base nos relatos dos trabalhadores da organização entrevistados, matizes da visão de mundo que, compartilhados durante os múltiplos processos socializadores vivenciados no órgão, favorecem a formação, ainda que limitada, de um fundo comum compartilhado (Borzeix \& Linhart, 1996). Este fundo, se não torna homogêneos os indivíduos, dota-os de alguns traços comuns, impactando sua forma de pensar e agir em sociedade, em conformidade com o papel desempenhado como membro da organização policial que representam.

O discurso organizacional de que a entrada naquela organização policial exige uma série de itens de conduta de seus trabalhadores - a incorporação de uma papel a ser representado - está presente e, em certos momentos, repetido pelos indivíduos que nela ingressaram. O policial reconhece em si atitudes introjetadas, após a entrada na polícia, que extrapolam a sua atuação profissional, influenciando sua forma de enxergar o mundo e as coisas que acontecem ao seu redor. Descrevendo-se, ou não, como um super-homem (Soares \& Musumeci, 2005), sente-se diferente. O convívio com instâncias até então desconhecidas em sociedade e o contato próximo e obrigatório com o perigo e com a criminalidade trazem a este indivíduo a sensação de diferença em relação ao cidadão comum que ele um dia já foi.

Nesse sentido, o trabalho na organização policial extrapola as relações objetivas de trabalho (Berger \& Lucman, 1985), atuando efetivamente sobre sua subjetividade. Essa assertiva traz consigo implicações não somente na atuação profissional do indivíduo como em sua vida pessoal. O trabalho extrapola o espaço e o tempo a ele destinado, para interferir na forma de ser e de pensar do trabalhador, atuando efetivamente na construção social do indivíduo (Freitas, 2000). No estudo realizado, foi possível perceber o indivíduo relatando, implícita ou explicitamente, o seu trabalho, a atividade policial, influenciando sua forma de ver e de se relacionar com mundo: os seus perigos, a necessidade de uma mudança de comportamento diante de determinadas situações e de condutas que deve ter em conformidade com a profissão que agora exerce.

Afora as questões que norteiam o comportamento do indivíduo, restaram, também, latentes determinados vínculos afetivos estabelecidos com a Instituição. Não obstante os relatos indicarem a Polícia Rodoviária Federal tão-somente como passagem na trajetória profissional traçada por estes indivíduos, um emprego escolhido por questões que extrapolam o trabalho a ser desempenhado, é evidente, por seu lado, a preocupação com a Instituição e a expectativa de um futuro melhor para esta, ainda que ele não esteja mais presente nela. Essa constatação permite concluir que as relações estabelecidas no âmbito da organização de alguma forma reificam a realidade (Penafiel \& Bellen, 2005), influenciando a percepção do indivíduo sobre a condição à qual está sendo submetido. A organização, ainda que não seja nobre, perfeita, grande e potente (Carrieri, 2001), persuade (Ramos, 1989) o indivíduo a assim desejá-la, demonstrando sua parcela de amor e devoção ao órgão (Enriquez, 2000). A organização torna-se para o indivíduo um ente querido, dotado de personalidade, que se espera ver sempre saudável e vigoroso. Tais vínculos se repetem, mesmo entre os membros da equipe (Goffman, 1985), os companheiros de sofrimento (Goffman, 1974). A solidariedade para dentro e o distanciamento para fora favorecem a formação de um espírito de corpo (Soares \& Musumeci, 2005) que permite aos colegas se protegerem das ameaças externas, procurando blindar a eles próprios e à organização.

Contudo, independentemente da constatação de semelhanças no modo de agir e de certa forma de ser destes indivíduos, outras questões despertam interesse, ao se concluir a presente pesquisa. Em que pese a evidência de um discurso individual alinhado com o discurso organizacional, preservando-se o órgão e seus preceitos, inúmeros são os ajustamentos (Goffman, 1985) das conveniências individuais à organização, resistindo à sua modelação pela organização. A partir do estudo ora desenvolvido, percebe-se que o alinhamento aos preceitos organizacionais se reveste também de uma estratégia para a sobrevivência no órgão. As práticas voltadas para que o indivíduo efetivamente vista a camisa (Morais, 2007), desde o Curso de Formação Profissional até os demais processos socializadores, 
vivenciados dentro do órgão, são não somente incorporadas, mas também apoiadas. Assim, não obstante a organização impor ao indivíduo uma visão de mundo repleta de regras de conduta a serem internalizadas, este também age, à sua forma, estabelecendo suas estratégias em relação ao "teste psicológico” (Entrevistado 4), que ele mesmo já diagnosticou.

Nessa linha, não há como descrever uma fórmula rígida e sem variáveis que possa responder com precisão em que medida a ideologia vivenciada na organização Polícia Rodoviária Federal contribui para a formação da identidade profissional do policial rodoviário federal, visto que cada processo de formação é único, em conformidade com as especificidades e as expectativas de cada indivíduo. A adesão do indivíduo ao discurso ideológico organizacional não parece estar afeita às suposições que, à luz da teoria pesquisada, orientaram a presente pesquisa. Não consta dos relatos dos entrevistados a narrativa de um processo claro e evidente de reconstrução pessoal que implique a formação estruturada de uma visão de mundo. As representações compartilhadas pelos indivíduos deste grupo surgem muito mais em decorrência do contato com essa nova experiência que apresenta o mundo policial, com os riscos e as demais particularidades desta profissão do que em virtude de uma tentativa elaborada pela organização para conquistar o imaginário do trabalhador. A homogeneidade e o espírito de corpo (Soares \& Musumeci, 2005) florescem muito mais da amizade e da cumplicidade resultantes da convivência em grupo do que de uma manifesta intenção de nivelamento ou padronização dos sujeitos.

Outro ponto que merece destaque é o fato de que, comumente, a escolha pela profissão não foi motivada inicialmente pela vocação profissional, mas pelas questões anteriormente elencadas na procura pelo emprego público. As afirmativas reforçam o pouco conhecimento prévio do trabalho do policial rodoviário federal. Tal fato parece dificultar a adesão subjetiva ao modo de ser da organização, passando a ser este o seu próprio modo de enxergar o mundo. $\mathrm{O}$ fato da escolha pelo cargo de policial dever-se prioritariamente à perspectiva ideológica macro, capitalista, e não micro, organizacional, traz consigo implicações. O foco individual no dinheiro, na lógica do sistema capitalista, impele o trabalhador a querer mais do que o sucesso da empresa e, em decorrência deste, o seu próprio sucesso. Nessa perspectiva macro o sucesso extrapola esta fronteira, transferindo para a sociedade a fronteira da realização subjetiva do indivíduo. Talvez daí advenha o interesse em obter sucesso em outros cargos, ganhando melhores salários, mais dinheiro, em outros órgãos públicos.

Espera-se, no final deste trabalho, ter oferecido contribuições para a compreensão da complexa temática em que se revela a subjetividade nas organizações. Independentemente das particularidades que cercam tanto a organização estudada quanto os indivíduos ouvidos, foram trazidas à baila alguns dos matizes que de, forma geral, circundam as práticas organizacionais à procura da conquista do imaginário do trabalhador (Carrieri, 2001), assim como as práticas dos trabalhadores à procura da sua sobrevivência dentro da organização. Em meio a essa relação em busca da dominação, encontra-se a visão de mundo compartilhada pela organização, ora incorporada, ora rejeitada, ora subvertida, em conformidade com a efetiva e particular submersão do indivíduo na organização.

Artigo recebido em 07.08.2008. Aprovado em 31.07.2009.

\section{REFERÊNCIAS BIBLIOGRÁFICAS}

Alberti, V. (1989). História oral: a experiência do Cpdoc. Rio de Janeiro: Centro de Pesquisa e Documentação de História Contemporânea do Brasil.

Alberti, V. (2004). Ouvir contar: textos em história oral. Rio de Janeiro: Editora FGV.

Bardin, L. (2005). Análise de conteúdo. Lisboa: Edições 70.

Berger, P. L., \& Luckman, T. (1985). A construção social da realidade: tratado de sociologia do conhecimento. Petrópolis: Vozes. 
Borzeix, A., \& Linhart, D. (1996) Identidades e práticas lingüísticas na empresa. In J. F. Chanlat (Org.). O indivíduo na organização: dimensões esquecidas (Vol. 3, pp. 82-106). São Paulo: Atlas.

Camargo, A. (1984). Os Usos da história oral e da história de vida: trabalhando com elites políticas. Revista de Ciências Sociais, 27(1), 5-28).

Carmo, M. S. F., Oliveira, J. A. P., \& Arruda, R. G. L. (2006, setembro). O trabalho com resíduos pelos classificadores - o papel da semântica do lixo no reconhecimento social e identidade profissional. Anais do Encontro Nacional da Associação Nacional de Pós-Graduação e Pesquisa em Administração, Salvador, BA, Brasil, 30.

Carrieri, A. P. (2001, setembro). As metáforas de identidade de uma empresa de telecomunicações antes e depois de sua privatização. Anais do Encontro Nacional da Associação Nacional de Pós-Graduação e Pesquisa em Administração, Campinas, SP, Brasil, 25.

Cruz, M. V. G. (2005). Para administrar a ordem pública e a aplicação da lei: formas de policiamento em uma perspectiva comparada Brasil - Estados Unidos: uma análise das experiências de Belo Horizonte, MG e Washington, D.C. Tese de doutorado, Centro de PósGraduação e Pesquisas em Administração, Universidade Federal de Minas Gerais, Belo Horizonte, MG, Brasil.

Cunha, N. V. da (2004). Como se "fabrica" um policial: algumas considerações em torno dos processos de socialização e formação profissional. Anais do Fórum Internacional de Formação Policial. Rio de Janeiro, RJ, Brasil, 4.

Eagleton, T. (1997). Ideologia. São Paulo: Boitempo.

Enriquez, E. (1997). A organização em análise. Petrópolis, Rio de Janeiro: Vozes.

Enriquez, E. (2000). Vida psíquica e organização: In F. C. Prestes Motta \& M. E. Freitas (Orgs.), Vida psíquica e organização (p. 11-22). Rio de Janeiro: Editora FGV.

Faria, J. H. (1987). Comissões de fábrica: poder e trabalho nas unidades produtivas. Curitiba: Criar.

Faria, J. H. (2005). Economia política do poder ( Vol. 2). Curitiba: Juruá.

Ferreira, M. M., \& Amado, J. (Coord.). (2002). Usos \& abusos da história oral (5a ed.). Rio de Janeiro: Editora FGV.

Foucault, M. (1977). Vigiar e punir: nascimento da prisão. Petrópolis: Vozes.

Freitas, M. E (2000). A questão do imaginário e a fronteira entre a cultura organizacional e a psicanálise. In F. C. P. Motta \& M. E. Freitas (Orgs.), Vida psíquica e organização (pp. 41-73). Rio de Janeiro: Editora FGV.

Goffman, E. (1974). Manicômios, prisões e conventos. São Paulo: Perspectiva.

Goffman, E (1975). Estigma: notas sobre a manipulação da identidade deteriorada. Rio de Janeiro: Zahar.

Goffman, E. (1985). A representação do eu na vida cotidiana. Petrópolis: Vozes.

Horochovski, R. R., \& Taylor, C. R. (2001). A estruturação do sujeito nas instituições e organizações: aspectos inconscientes no cotidiano organizacional. Revista Spei, 2(2), 37-47.

Kassar, M. C. M. (2000). Marcas da história social no discurso de um sujeito: Uma contribuição para a discussão a respeito da constituição social da pessoa com deficiência. Cadernos CEDES, 20(50), 41-54. 
Konder, L. (2002). A questão da ideologia. São Paulo: Companhia das Letras.

Lapierre, L. (1994). Interioridade, gestão e organização da realidade psíquica como fundamento da gestão. In J. F. Chanlat (Org.), O indivíduo na organização: dimensões esquecidas (Vol. 2). São Paulo: Atlas.

Laville, C., \& Dionne, J. (1999). A construção do saber: manual de metodologia da pesquisa em ciências humanas. Belo Horizonte: UFMG.

Listgarten, S. C. (2002). Diagnóstico identitário da policial militar feminina na polícia militar de Minas Gerais. Monografia, Fundação João Pinheiro, Belo Horizonte, Minas Gerais, Brasil.

Löwy, M. (1993). Ideologias e ciência social: elementos para uma análise marxista. São Paulo: Cortez.

Machado, H. V., \& Crubellate, J. M (2006, setembro). Identidade e imagem organizacional como fenômenos simultâneos e complementares. Anais do Encontro Nacional da Associação Nacional de Pós-Graduação e Pesquisa em Administração, Salvador, BA, Brasil, 30.

Marre, J. L. (1991). História de vida e método biográfico. Cadernos de Sociologia, 3(3) , 89-141.

Martins, F. R., \& Bulgacov, Y. L. M. (2006, setembro). Controle organizacional: o discurso da organização nas narrativas de identidade social do trabalhador de uma indústria de grande porte do ABC paulista. Anais do Encontro Nacional da Associação Nacional de Pós-Graduação e Pesquisa em Administração, Salvador, BA, Brasil, 30.

Morais, L. L. P. (2007, setembro). Vestindo a camisa: aspectos ideológicos do uso da farda. Um estudo de caso em uma unidade policial. Anais do Encontro Nacional da Associação Nacional de Pós-Graduação e Pesquisa em Administração, Rio de Janeiro, RJ, Brasil, 31.

Neves, L. A. (2001, agosto). História oral. Palestra proferida no Encontro Estadual de História e III Encontro Nordeste de História Oral, Teresina, PI, Brasil, I.

Paes de Paula, A. P., \& Wood, T., Jr. (2002). Pop-management: contos de paixão, lucro e poder. Revista Organizações e Sociedade, 9(24), 39-51.

Penafiel, F. M. M., \& Bellen, H. M. V. (2005, setembro). Ideologia do movimento ambientalista: um estudo de casos múltiplos em quatro organizações não governamentais de Florianópolis - S.C. Anais do Encontro Nacional da Associação Nacional de Pós-Graduação e Pesquisa em Administração, Brasília, DF, Brasil, 29.

Ramos, G. (1989). A nova ciência das organizações. Rio de Janeiro: Editora da Fundação Getúlio Vargas.

Roux, J. (1983). Recursos humanos e treinamento. São Paulo: Brasiliense.

Silva, R. A. R. (2006, setembro). Telecomuters: desconstrução e reconstrução dos conceitos de subjetividade no mundo do trabalho. Anais do Encontro Nacional da Associação Nacional de Pós-Graduação e Pesquisa em Administração, Salvador, BA, Brasil, 30.

Soares, B. M., \& Musumeci, L. (2005). Mulheres policiais: presença feminina na polícia militar do Rio de Janeiro. Rio de Janeiro: Civilização Brasileira.

Toledo, S. (2006, setembro). Carreira e identidade: reflexos das exigências mercadológicas na vida pessoal e profissional dos jovens executivos de empresas multinacionais. Anais do Encontro Nacional da Associação Nacional de Pós-Graduação e Pesquisa em Administração, Salvador, BA, Brasil, 30 . 
Vergara, S. C. (2005). Métodos de pesquisa em administração. São Paulo: Atlas.

Vergara, S. C. (2006). Projetos e relatórios de pesquisa em administração (7a ed.). São Paulo: Atlas.

Vigotski, L. S. (2003). A formação social da mente: o desenvolvimento dos processos psicológicos superiores. São Paulo: Editora Martins Fontes. 